Available online on 15.11.2016 at http://jddtonline.info
O 2016, publisher and licensee JDDT, This is an Open Access article which permits unrestricted
noncommercial use, provided the original work is properly cited

Research Article

\title{
Transdermal Delivery Of FluCONAZOLE MicrosPonges: PREPARATION AND IN VITRO CHARACTERIZATION
}

\author{
S. Dineshmohan ${ }^{1 *}$, V. Rama Mohan Gupta ${ }^{2}$ \\ ${ }^{1}$ *Department of Pharmaceutics, Vishnu Institute of Pharmaceutical Education and Research, Narsapur 502313, Hyderabad, \\ Telangana, INDIA \\ ${ }^{2}$ Department of Pharmaceutics, Pullareddy Institute of Pharmacy, Annaram, Hyderabad, Telangana, INDIA
}

\begin{abstract}
The pivotal objective of this investigation was to formulate Fluconazole microsponge by emulsion solvent diffusion technique in order to provide sustained release. Microsponge was formulated by emulsion solvent diffusion technique with varied drug-polymer ratios. Ethyl cellulose was used as release retarding material and polyvinyl alcohol was used as a surfactant. The prepared microsponges were characterized by Scanning electron microscopy, Fourier transform infrared spectroscopy, particle size analysis, and evaluated for surface morphology, drug loading, in vitro drug release as well. The formulated microsponges are spherical with a porous surface and $108.16 \mu \mathrm{m}$ of mean particle size. The microsponges were then incorporated into the carbopol gel. The In vitro drug release results showed that microsponges with 1:1.5 drug-polymer ratios were more effective to make a prolonged drug release of $74.2 \%$ at the end of 8 hours. Thus the formulated microsponge-based gel of fluconazole would be a hopeful choice for formal therapy for safe and effective treatment of fungal infections.
\end{abstract}

Key Words: Fluconazole, Microsponge, Ethyl cellulose, Scanning electron microscopy, particle size and in vitro drug release.

\begin{abstract}
*Corresponding author
S. Dineshmohan, Associate Professor, Department of pharmaceutics, Vishnu Institute of Pharmaceutical Education and Research, Narsapur, 502313 Medak (Dt), Hyderabad, Telangana. Mobile: +91 8008777734, E-mail address: dineshmohan.s@ viper.ac.in

Article Info

Received 16 Sep 2016; Review Completed 25 Sep 2016; Accepted 20 Oct 2016, Available online 15 Nov 2016

URI: http://jddtonline.info/index.php/jddt/article/view/1334

Cite this article as:

Dineshmohan S., Gupta V.R.M., Transdermal delivery of fluconazole microsponges: preparation and in vitro characterization, Journal of Drug Delivery \& Therapeutics. 2016; 6(6):7-15 DOI: http://dx.doi.org/10.22270/jddt.v6i6.1334
\end{abstract}

\section{INTRODUCTION}

Fluconazole is a synthetic antifungal agent belonging to the group of triazole. It is one of the commonly used antifungal agents for most kinds of fungal infections; including superficial and invasive fungal infections. Regrettably fluconazole oral administration has limitations such as nausea, vomiting, bloating and abdominal discomfort. Alongside most of the time the parenteral administration of fluconazole led to skin rashes and itching. ${ }^{2}$ For these reasons, now a day's advance localized and transdermal delivery has gained a lot of importance. ${ }^{3,4}$

The conventional gel formulation of fluconazole causes cutaneous irritation and prolonged use led to dermal hypersensitivity. Hence, a novel system necessitates which will increase the presence of active agents either on the skin surface or within the epidermis, concurrently reducing hasty transdermal penetration. Many researchers have attempted to develop novel transdermal formulations of fluconazole. Accordingly, the objective 
of our research is to formulate and evaluate fluconazole microsponge loaded carbopol gel for safe, effective and stable gel and evaluate the in-vitro sustained release performance. Microsponge-based delivery systems (MDS) give assurance of drug legalization on the skin surface and within the epidermis without entering into the systemic circulation in greater extent; thereby reducing systemic and local cutaneous adversities. They also offer an advantage of programmable release and are biologically safe. Additionally, this technology presents quite a lot of benefits via drug entrapment by means of better formulation flexibility, abridged side effects, improved elegance and superior stability. ${ }^{5-8}$

\section{MATERIALS AND METHODS}

\section{Materials}

Fluconazole was obtained as a gift sample from RMS Research labs Pvt Ltd Hyderabad. Ethyl cellulose was gifted by Yeluri formulations, Hyderabad. Polyvinyl alcohol, triethyl citrate and ethyl acetate were purchased from Emerck (India) Ltd., Mumbai. All other chemicals and solvents used are of analytical grade.

\section{Methods}

\section{Formulation of Fluconazole microsponge}

Fluconazole loaded microsponges were prepared by quasi-emulsion solvent diffusion technique ${ }^{9}$. The internal phase was encompassed ethyl cellulose and triethylcitrate (TEC) both were dissolved in $10 \mathrm{ml}$ of ethyl acetate. TEC was used as plasticizer. This was, followed by addition of fluconazole with stirring. The internal phase was then poured into polyvinyl alcohol (PVA) solution in water, the external phase. Then the final mixture was filtered through filter paper with a pore size of $0.45 \mu \mathrm{m}$ to separate formed microsponges and dried at room temperature for further studies.

\section{Calculation of production yield, actual drug content and entrapment efficiency}

The production yield (PY) was determined by following formula accurately calculating the initial weight of the raw materials and the weight of the obtained microsponge particles. Samples of drug loaded microsponges $(20 \mathrm{mg})$ were dissolved in $10 \mathrm{ml}$ phosphate buffer $\mathrm{pH} 5.5$ under sonication for $20 \mathrm{~min}$ at $25^{\circ} \mathrm{C}$. The samples were filtered using $0.45 \mu \mathrm{m}$ membrane filter and analyzed for FLZ content spectrophotometrically using Shimadzu UV-1650 UVVIS double beam spectrophotometer (Shimadzu, Japan) at $260 \mathrm{~nm}$. The actual drug content and EE were calculated as given below. ${ }^{10,11}$

The actual drug content $(\%)=\left(\mathrm{M}_{a c t} / \mathrm{M}_{m s}\right) \times 100$

The EE (\%) was calculated according to the following equation:

Entrapment efficiency $=\left(\mathrm{M}_{a c t} / \mathrm{M}_{\text {the }}\right) \times 100$

Where $\mathbf{M}_{\mathrm{act}}$ is the actual fluconazole content with weighed quantity of the microsponge, $\mathbf{M}_{m s}$ is the weighed quantity of powder of microsponges, and $\mathrm{M}_{\text {the }}$ is the theoretical amount of fluconazole in microsponge calculated from the quantity added during preparation. All the experiments were performed in triplicate and the mean of the values was reported.

\section{Particle size analysis}

Particle size analysis of prepared microsponges was carried out using particle size analyzer (Malvern Mastersizer Hydro 2000, Ver.5.54 Malvern, UK) which allows sample measurement in the range of 0.020-2000 $\mathrm{mm}$ and the particle refractive index were set to 1.520 . Microsponges were dispersed in double distilled water before running the sample in instrument to ensure that light scattering signal (as indicated by particle count per second) is within the sensitivity range of the instrument ${ }^{12}$.

\section{Fourier Transform Infrared studies}

IR spectra of the pure drug, other excipients and formulations were obtained and compared. In the present study, potassium bromide $(\mathrm{KBr})$ pellet method was employed. The samples were thoroughly mixed with dry powder of potassium bromide and scanned from $4000-400 \mathrm{~cm}^{-1}$ by FT-IR spectrophotometer (Model number 02437 Shimadzu, India) ${ }^{13}$

\section{Scanning electron microscopy studies}

The morphology and appearance of the microsponges were studied using SEM (SEM-JEOL Instrument, JSM6360, Japan) operating at $15 \mathrm{KV}$. The samples were dusted onto double-sided tape on a metal stub and coated with gold/palladium alloy under vacuum. The obtained photograph was recorded at $\mathrm{x} 500$ magnification $^{14}$.

\section{Formulation of fluconazole microsponge gel}

To obtain a suitable topical formulation for application, microsponges were incorporated into a gel base. After the preliminary tests carbopol was found to be an ideal choice. $0.5 \mathrm{~g}$ of Carbopol 934 was uniformly dispersed in beakers containing a sufficient quantity of water and was allowed to hydrate overnight. Then it was mixed with $5 \mathrm{~g}$ of glycerin with methyl paraben to form a paste. Next, $95 \mathrm{ml}$ of water was added slowly to paste under constant stirring, followed by the drop wise Triethanolamine addition to adjust $\mathrm{pH}$ to 6.5-7.5. A calculated amount of FLZ microsponge was incorporated which makes the final concentration of fluconazole in the gel is $1 \% \mathrm{w} / \mathrm{w}^{15}$.

\section{Evaluation of microsponge loaded carbopol gel}

\section{Homogenicity}

The prepared gels were visually inspected for clarity, color and transparency. The prepared gels were also evaluated for the presence of any particles. Smears of gels were prepared on a glass slide and observed under the microscope for the presence of any particle or grittiness $^{16,17}$.

\section{pH}

The $\mathrm{pH}$ of the prepared fluconazole loaded microsponge gel was measured using $\mathrm{pH}$ - meter (LI-120 Digital PH 
Meter) by putting the tip of the electrode into the gel and after 2 minutes the result was recorded ${ }^{16,17}$.

\section{Spreadability}

A sample of $0.1 \mathrm{~g}$ of gel was pressed between 2 slides with $500 \mathrm{~g}$ weights and left for about $5 \mathrm{~min}$ where no more spreading was expected. Diameters of spread circles were measured in $\mathrm{cm}$ and were taken as comparative values for spreadability (diameter of the spread circle - initial diameter ${ }^{16,17}$.

$\mathrm{S}=M L / \mathrm{T}$

Where $M=$ weight (in g) attached to upper slide, $L=$ length (in $\mathrm{cm}$ ) of glass slides, and

$T=$ time (in s) taken to separate the slides.

Wooden block-glass slide apparatus was used and by applying weight about $20 \mathrm{~g}$, time for complete separation of the upper slide (movable) from a lower slide (fixed) was estimated

\section{Viscosity}

The viscosity of fluconazole loaded microsponge carbopol gel was measured in Brookfield Viscometer, model- VL2 (Lemis Baltic) with spindle No $4^{16,17}$.

\section{In vitro drug release}

The in vitro release of gel formulations was studied using Franz diffusion cells. The cellophane membrane $(0.45 \mu \mathrm{m})$ previously soaked overnight in dissolution medium was mounted onto Franz diffusion cell with $15 \mathrm{ml}$ receptor compartment and effective diffusion area $2.84 \mathrm{~cm}^{2}$. PBS ( $\mathrm{pH} \mathrm{7.4)}$ was used as receptor medium, and system was thermostated to $37 \pm 1^{\circ} \mathrm{C}$ under constant stirring. All batches of drug microsponge gels (F1-F10) were conducted for the diffusion study. Aliquots of $1 \mathrm{ml}$ volume were withdrawn at specific time intervals by maintaining sink condition. Withdrawn aliquots were then diluted using receptor medium and analyzed by a UV spectrophotometer (Shimadzu 1601, Kyoto, Japan) at $260 \mathrm{~nm}$ against PBS $\mathrm{pH}$ 7.4. To reveal the drug release mechanism and contrast, release profiles disparities among formulations, data obtained from timely drug release were used. Further, release data were analyzed by means of diverse mathematical models to know release kinetics ${ }^{18}$.

\section{Accelerated stability studies}

According to an in vitro release profile F3 formulation was selected as optimized formulation and which was subjected to stability studies as per ICH. $5 \mathrm{gm}$ of gel was filled with collapsible aluminum tubes and kept at $5^{\circ} \mathrm{C}$, $25^{\circ} \mathrm{C} / 60 \% \mathrm{RH}, 30^{\circ} \mathrm{C} / 65 \% \mathrm{RH}$ and $40^{\circ} \mathrm{C} / 75 \% \mathrm{RH}$ for a period of three months. The samples were withdrawn at specific time intervals $(15,30,60$ and 90 days) and evaluated for physical appearance, $\mathrm{pH}$, homogeneity, spreadability, viscosity and drug release profiles ${ }^{19}$.

\section{Drug release kinetics}

To analyze the mechanism of fluconazole release from the formulations, the in vitro release data were fitted into various release kinetic models. The models used are: zero order, first order, Higuchi model and Korsmeyer - Peppas. The model with the highest correlation coefficient was considered to be the best fitted model $^{20}$.

\section{RESULTS AND DISCUSSIONS}

\section{Formulation of Fluconazole microsponge}

Quasi-emulsion solvent diffusion method was used for the preparation of fluconazole microsponges and it has the following advantages like easy, rapid, cost effective and avoiding solvent toxicity ${ }^{9}$. Ethyl acetate and water were used as internal phase and external phases for the preparation of fluconazole microsponges. The drug and polymer solubility, rate of diffusion into the internal phase, were used to provide good spherical porous microsponges Figure1.

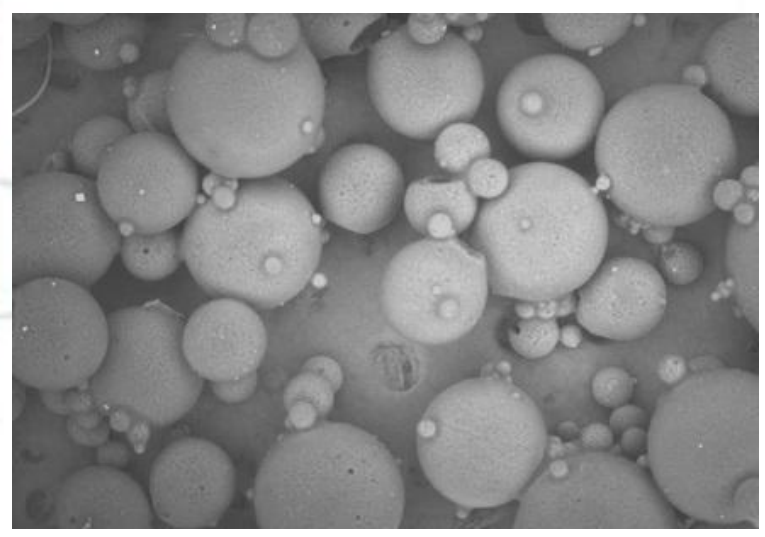

Figure 1: Scaning Electron Microspcopy of Fluconazole loaded microsponge

Table 1: Composition of Fluconazole microsponges

\begin{tabular}{|c|c|c|c|c|c|c|c|c|c|c|}
\hline Ingredients & \multicolumn{10}{|c|}{ Formulation batches of Fluconazole microsponge } \\
\hline & F1 & F2 & F3 & F4 & F5 & F6 & F7 & F8 & F9 & F10 \\
\hline D/P ratio & $1: 0.5$ & $1: 1$ & $1: 1.5$ & $1: 2$ & $1: 2.5$ & $1: 3$ & $1: 1.5$ & $1: 1.5$ & $1: 1.5$ & $1: 1.5$ \\
\hline Ethyl Acetate (ml) & 10 & 10 & 10 & 10 & 10 & 10 & 10 & 10 & 10 & 10 \\
\hline Tri ethyl citrate (ml) & 1 & 1 & 1 & 1 & 1 & 1 & 1 & 1 & 1 & 1 \\
\hline PVA (\%w/v) & 0.75 & 0.75 & 0.75 & 0.75 & 0.75 & 0.75 & 0.45 & 0.6 & 0.9 & 1 \\
\hline Water (ml) & 90 & 90 & 90 & 90 & 90 & 90 & 90 & 90 & 90 & 90 \\
\hline
\end{tabular}

$\mathrm{D} / \mathrm{P}$ ratio = Drug: Polymer ratio, $\mathrm{PVA}=$ Poly vinyl alcohol 


\section{Fourier Transform Infrared studies}

The IR spectra of pure fluconazole and formulation are shown in Figure \& Table. The peak at $3120 \mathrm{~cm}-1$ indicate $\mathrm{O}-\mathrm{H}$ stretching, $3012 \mathrm{~cm}-1$ for the $\mathrm{C}-\mathrm{H}$ stretching, $1620 \mathrm{~cm}-1$ for the aromatic $\mathrm{C}=\mathrm{C}$ stretching,
$1597 \mathrm{~cm}-1$ for the N-H bending, $1354 \mathrm{~cm}-1$ for the $\mathrm{C}-\mathrm{H}$ bending. These are the major spectral peaks of the drug. All these peaks were present in the formulations and thus this confirms that the drug did not have any interaction with the excipients. Results are shown in Figures 2, 3 \& Table 2

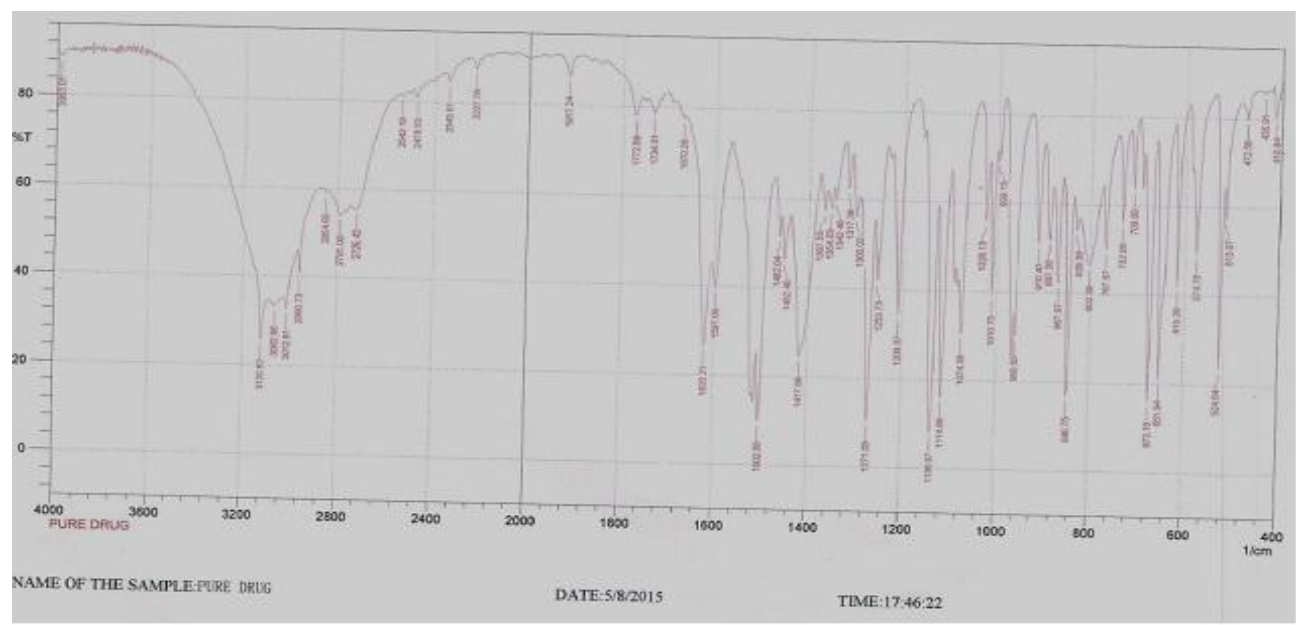

Figure 2: FT-IR Spectra of Drug

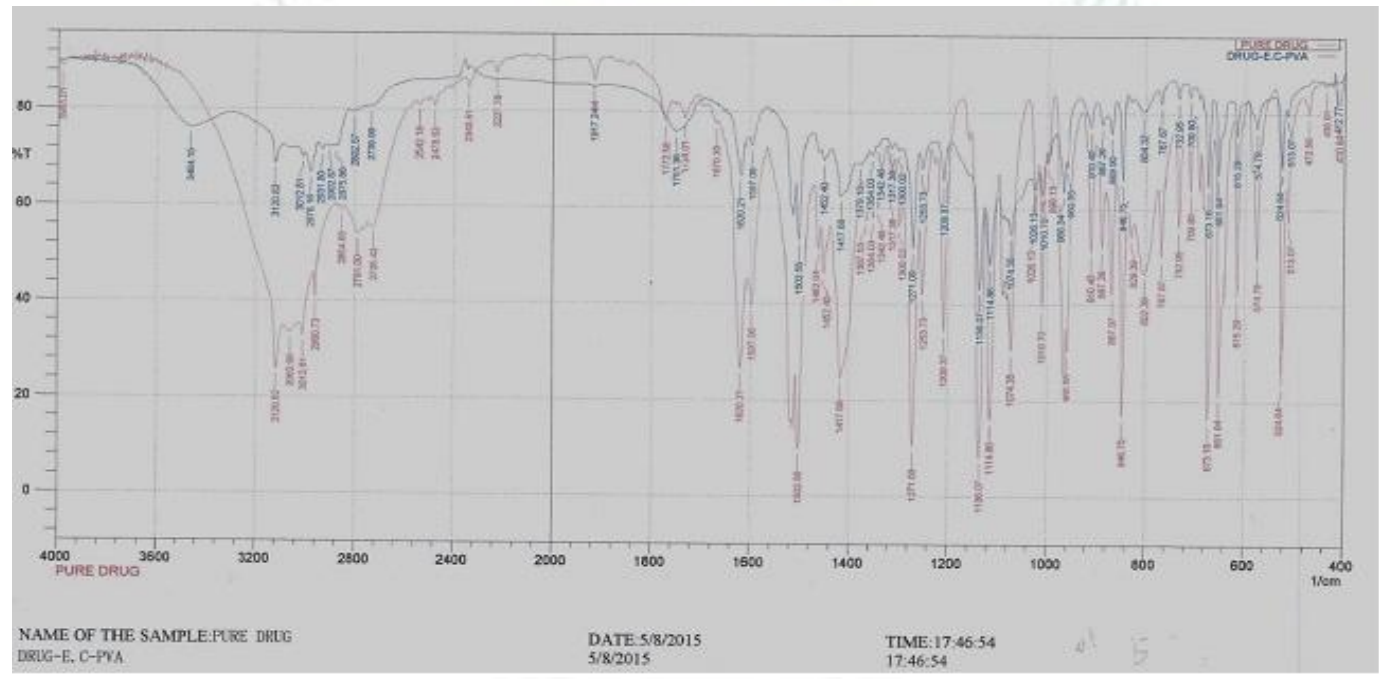

Figure 3: FT-IR Spectra of Drug +Ethyl cellulose and Poly vinyl alcoho

Table 2: Relevant bands of drug \& physical mixture in their FT-IR Spectra

\begin{tabular}{|c|c|c|c|c|}
\hline S.No & Functional group & Pure Drug & Physical Mixture & Type of vibration \\
\hline 1 & O-H & 3120.82 & 3120.82 & Stretching \\
\hline 2 & C-H & 3012.61 & 3012.61 & Stretching \\
\hline 3 & C =C Ar & 1620.21 & 1620.21 & Stretching \\
\hline 4 & N-H & 1597.06 & 1597.06 & Bending \\
\hline 5 & C-H & 1354.03 & 1354.03 & Bending \\
\hline
\end{tabular}

\section{Scanning electron microscopy}

The morphology of the prepared microsponges was studied by SEM analysis. The shape and surface characteristics of the microsponges are shown in Figure 1. The microsponges were finely spherical and uniform in shape, highly porous in nature. The pores were created by the diffusion of solvent from surface of microsponges. The obtained SEM photograph was recorded at $\times 500$ magnification. The captured images of microsponges are shown in Figure 4. 


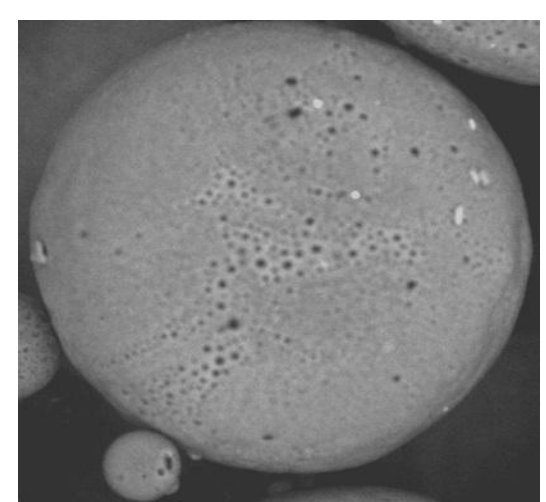

Figure 4: Scaning Electron Microspcopy Image of microsponge surface

Production yield actual FLZ content, and entrapment efficiency (EE \%)

The effect of the D/P ratio of production yield, encapsulation efficiency and drug content are shown in Table. It revealed that drug encapsulation efficiency did not attain $100 \%$, this might be due to fewer quantity of the drug gets dissolved in either phase. The production yield of all batches of fluconazole microsponges were ranged from $20.12 \%$ to $74.24 \%$. The D/P ratio and PVA concentration were found to affect production yield significantly. A low production yield was noticed in a $\mathrm{D} / \mathrm{P}$ ratio of 1:0.5 (F1), whereas, in $\mathrm{D} / \mathrm{P}$ ratio $1: 3(\mathrm{~F} 6)$ production yield was remarkably high i.e. $74.24 \%$. The results indicated that higher the $\mathrm{D} / \mathrm{P}$ ratio, higher the production yields. Besides this, the concentration of PVA also is equally responsible for production yield. Lower the PVA concentration, i.e. $0.45 \% \mathrm{w} / \mathrm{v}$ yields less production $33.37 \%(\mathrm{~F} 7)$ and as the concentration was increased to $0.9(\% \mathrm{w} / \mathrm{v})$ the production yield was also found to be increased up to $51.64 \%$ (F8, F9). But in the case of (F10) less production yield was noticed, the reason is might be due to the presence of excessive amount of surfactant $1.0 \% \mathrm{w} / \mathrm{v}$ it was responsible for more foam due to which less production yield was noticed $31.64 \%$ Rate of solvent diffusion from inner phase to outer phase took more time for formation of droplet and this might be the reason for high production yield. The encapsulation efficiencies were in the range of $64.12-91.35 \%$ as shown in Table 3. The outcome of encapsulation efficiency reflected that increasing the $\mathrm{D} / \mathrm{P}$ ratios (F1-F6) led to decrease drug loadings. The results were depicted in Table 3 .

Table 3: Actual drug content, encapsulation efficiency and production yield

\begin{tabular}{|c|c|c|c|c|c|}
\hline Code & D/P ratio & $\begin{array}{c}\text { Theoretical drug } \\
\text { content }(\boldsymbol{\%})\end{array}$ & $\begin{array}{c}\text { Actual drug } \\
\text { content }(\boldsymbol{\%}) \mathbf{\pm} \text { SD }\end{array}$ & $\begin{array}{c}\text { Encapsulation } \\
\text { efficiency }(\boldsymbol{\%}) \pm \mathbf{S D}\end{array}$ & $\begin{array}{c}\text { Production yield } \\
(\boldsymbol{\%}) \mathbf{\text { SD }}\end{array}$ \\
\hline F1 & $1: 0.5$ & 75 & $72.58 \pm 0.01$ & $85.56 \pm 0.01$ & $32.12 \pm 0.21$ \\
\hline F2 & $1: 1$ & 60 & $58.02 \pm 0.02$ & $85.12 \pm 0.02$ & $34.60 \pm 0.20$ \\
\hline F3 & $1: 1.5$ & 53 & $50.46 \pm 0.01$ & $84.10 \pm 0.03$ & $38.40 \pm 0.39$ \\
\hline F4 & $1: 2$ & 41 & $37.23 \pm 0.14$ & $83.42 \pm 0.01$ & $40.00 \pm 0.01$ \\
\hline F5 & $1: 2.5$ & 36 & $32.16 \pm 0.02$ & $82.10 \pm 0.03$ & $45.13 \pm 0.04$ \\
\hline F6 & $1: 3$ & 28 & $30.16 \pm 0.02$ & $80.10 \pm 0.03$ & $52.24 \pm 0.02$ \\
\hline F7 & $1: 1.5$ & 53 & $49.35 \pm 0.01$ & $89.37 \pm 0.21$ & $33.37 \pm 0.04$ \\
\hline F8 & $1: 1.5$ & 53 & $49.27 \pm 0.02$ & $82.62 \pm 0.01$ & $37.52 \pm 0.11$ \\
\hline F9 & $1: 1.5$ & 53 & $49.83 \pm 0.01$ & $46.12 \pm 0.02$ & $43.31 \pm 0.17$ \\
\hline F10 & $1: 1.5$ & 53 & $51.13 \pm 0.02$ & $49.10 \pm 0.01$ & $31.64 \pm 0.15$ \\
\hline
\end{tabular}

\section{Particle size}

The average particle size of microsponge formulations should be in the range of 5-300 $\mu \mathrm{m}$. The Particle size distribution of $\mathrm{F} 3$ formulation has been performed by laser light-scattering technique a particle size distribution map by volume of the fluconazole microsponge was identified, which showed that the specific area surface diameter and diameter by volume of the particles were $0.19 \mathrm{~m}^{2} / \mathrm{g}, 30.22 \mu \mathrm{m}$ and $55.9 \mu \mathrm{m}$ respectively. The particle size distribution of $\mathrm{d}(0.1), \mathrm{d}$ (0.5) and $d(0.9)$ were $17.27 \mu \mathrm{m}, 47.49 \mu \mathrm{m}$ and 108.6 $\mu \mathrm{m}$ respectively and the uniformity was 0.587 . Figure 5 .

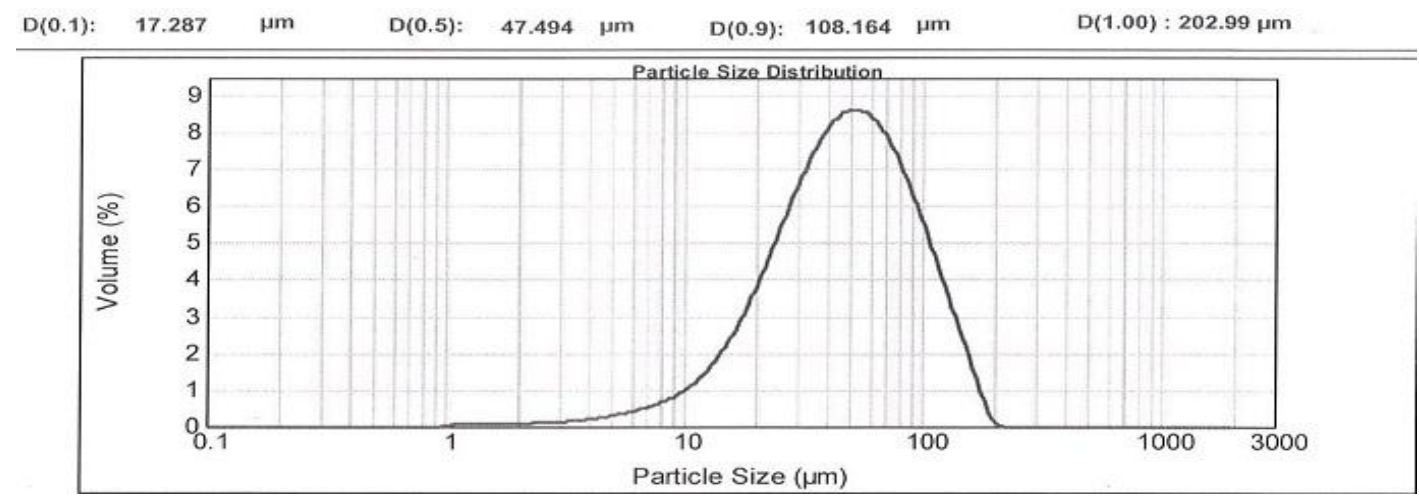

Figure 5: Particle size distribution curve of microsponges of (Optimized batch) 
Evaluation of fluconazole microsponge loaded carbopol gel

\section{Visual inspection}

The prepared fluconazole loaded microsponge gel formulations were inspected visually for their color, texture and appearance. All prepared formulations were White, viscous in nature with smooth texture and of good homogeneity without lumps

\section{pH measurement}

The $\mathrm{pH}$ values of all prepared formulations were found in the range of $6.5-7$, this is due to neutralization of formula by tri ethanol amine.

\section{Spreadability test}

Spreadability is one of the important characteristic of topical formulations and it helps to transfer correct dosage to the target site and make ease of application. Fluconazole microsponge loaded carbopol 934 forms a gel with spreadability ranges between to $2.10-4.38$ $\mathrm{gcm} / \mathrm{s}$. There was a slight decrease in spreading diameters of formulations of F4-F6; this variation was might be due to increased polymer concentration in microsponge.

\section{Viscosity measurement}

The viscosity of prepared fluconazole microsponge gel was measured in L4 Spindle Brookefield Viscometer, model- VL2, manufacturer Lemis Baltic and was found to be in the range $25030 \mathrm{cPs}$ to $47390 \mathrm{cPs}$. The results were depicted in Table 4.

Table 4: Physicochemical evaluation of fluconazole microsponge carbopol gel formulations

\begin{tabular}{|c|l|c|c|c|c|}
\hline Code & Physical appearance & $\mathbf{p H}$ & Spreadability & Homogenesity & Viscosity \\
\hline F1 & Transparent gel & $6.5 \pm 0.03$ & $4.38 \pm 0.5$ & Homogeneous & 25,030 \\
\hline F2 & Transparent gel & $6.5 \pm 0.02$ & $3.95 \pm 0.4$ & Homogeneous & 29,630 \\
\hline F3 & Transparent gel & $6.8 \pm 0.01$ & $3.31 \pm 0.3$ & Homogeneous & 34,520 \\
\hline F4 & Transparent gel & $6.5 \pm 0.01$ & $3.10 \pm 0.3$ & Homogeneous & 38,630 \\
\hline F5 & Transparent gel & $6.8 \pm 0.02$ & $2.45 \pm 0.5$ & Homogeneous & 40,630 \\
\hline F6 & Transparent gel & $7.0 \pm 0.04$ & $2.10 \pm 0.5$ & Homogeneous & 47,390 \\
\hline F7 & Transparent gel & $7.0 \pm 0.03$ & $3.30 \pm 0.6$ & Homogeneous & 33,820 \\
\hline F8 & Transparent gel & $7.0 \pm 0.03$ & $3.41 \pm 0.8$ & Homogeneous & 33,620 \\
\hline F9 & Transparent gel & $6.5 \pm 0.04$ & $3.20 \pm 0.6$ & Homogeneous & 34,500 \\
\hline F10 & Transparent gel & $6.8 \pm 0.04$ & $3.10 \pm 0.6$ & Homogeneous & 34,540 \\
\hline
\end{tabular}

\section{In vitro drug release study}

The in vitro dissolution profile was done for fluconazole microsponge formulas (F1-F10). From the in vitro release data it was noticed that the drug release was reduced from $94.10-42.70 \%$, this is due to $\mathrm{D} / \mathrm{P}$ ratio has increased i.e. the amount of polymer available was more in each formulation. It led to thickening of the polymer matrix wall, thus lesser drug release was occurring.
$94.10 \%$ of drug release was found in the highest drug release (F1) within $4 \mathrm{Hrs}$, while the lowest $42.70 \%$ for F6 at the end of $8 \mathrm{Hrs}$. It has been reported that by increasing the amount of PVA from batches F7 to F10, there was no significant change in the drug release pattern as compared with F3 formulation. Cumulative drug release of all batches F1-F6 and F7-F10 was shown in Figure 6, 7. According to in vitro release data formulation code F3 was selected as optimized batch.

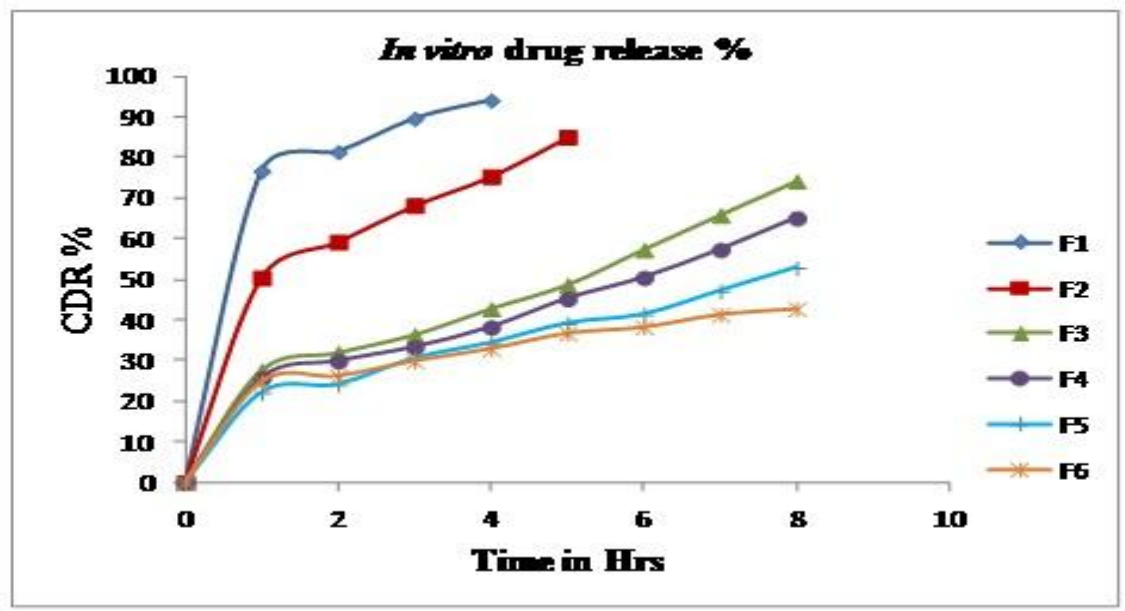

Fig 6: Dissolution profile of Fluconazole from microsponge (F1-F6) 


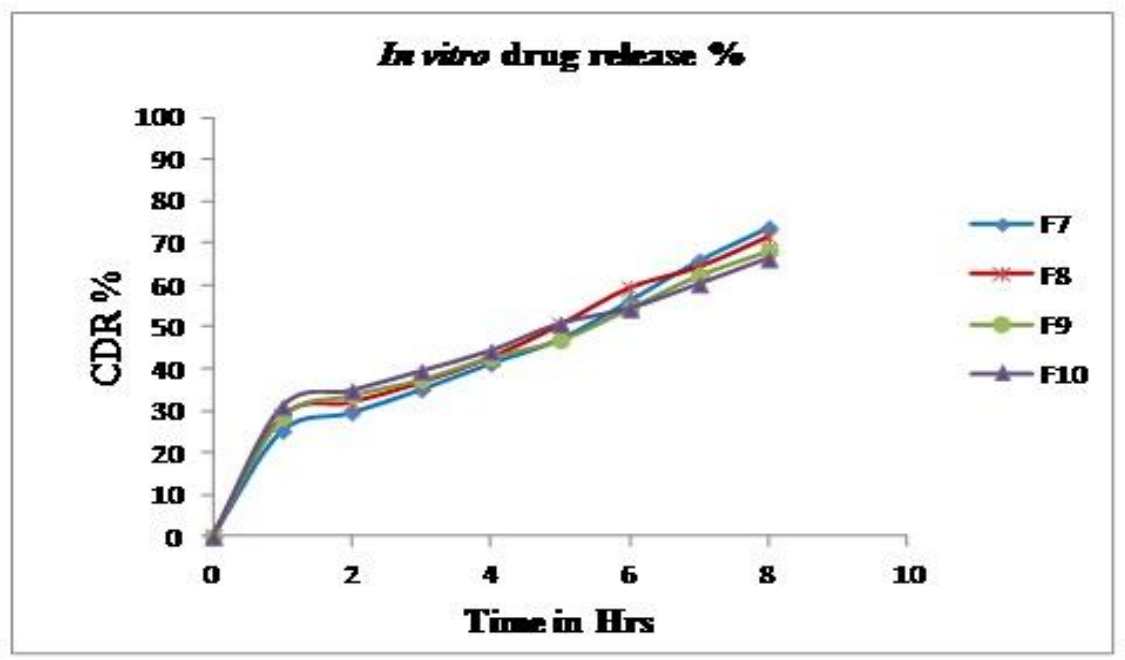

Figure 7: Dissolution profile of Fluconazole from microsponge (F7-F10)

Table 5: Physicochemical evaluation of microzsponge loaded carbopol gel during stability period

\begin{tabular}{|c|c|c|c|c|c|c|}
\hline F.Code & Appearance & Homogenicity & Spread ability & Viscosity & pH & \% drug release \\
\hline F3 & White & Homogeneous & 3.31 & 34,480 & $6.8 \pm 0.01$ & $73.0 \pm 0.01$ \\
\hline
\end{tabular}

\section{Drug release kinetics}

The drug release kinetic data are represented in Figure 8-11. From the graphical representation it can be understood that this layer is best fit in to Zero order kinetics which had shown a regression coefficient $\left(\mathrm{R}^{2}\right)$ of 0.9831 .

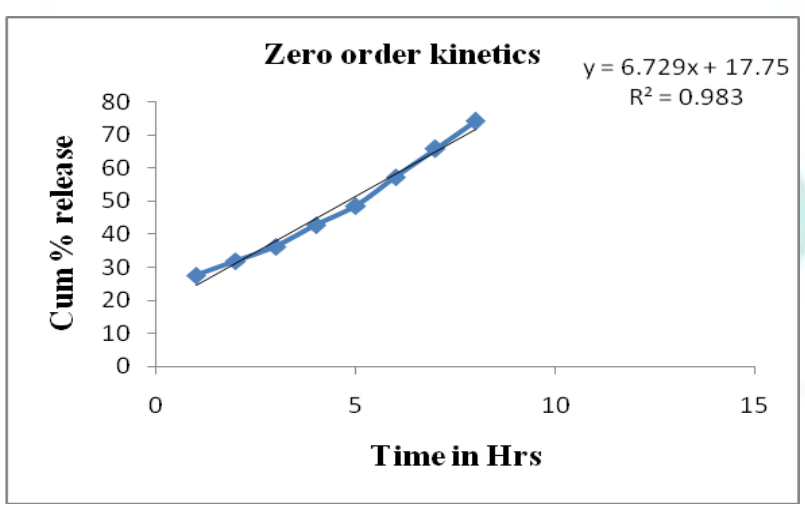

Figure 8: Zero order kinetic model

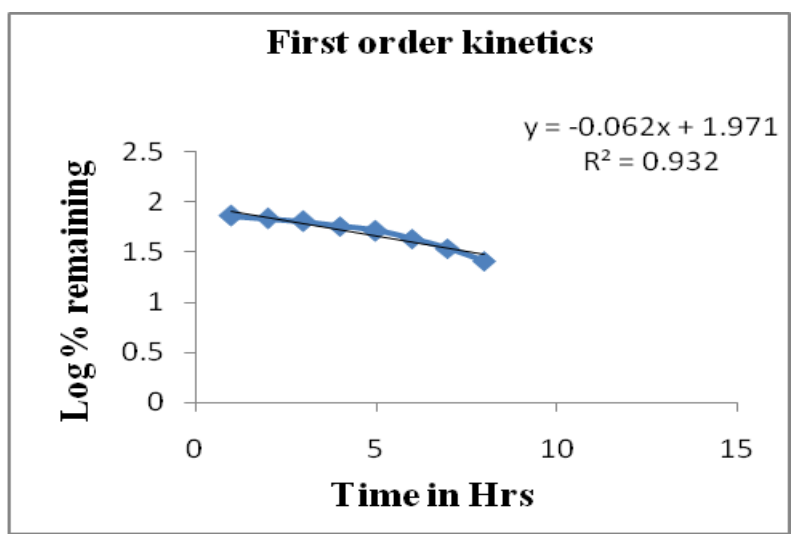

Figure 9: First order kinetics model 


\section{Stability study}

During stability studies, formulation was found to be a White, homogenous, smooth and no changes in $\mathrm{pH}$. It was also noticed that there were no changes in spreadability but slight changes in viscosity and drug release. Therefore, drug degradation was not observed. From that above data it has been proved that the formulation was stable over the period of 3 months. The results were shown in Figure 12.

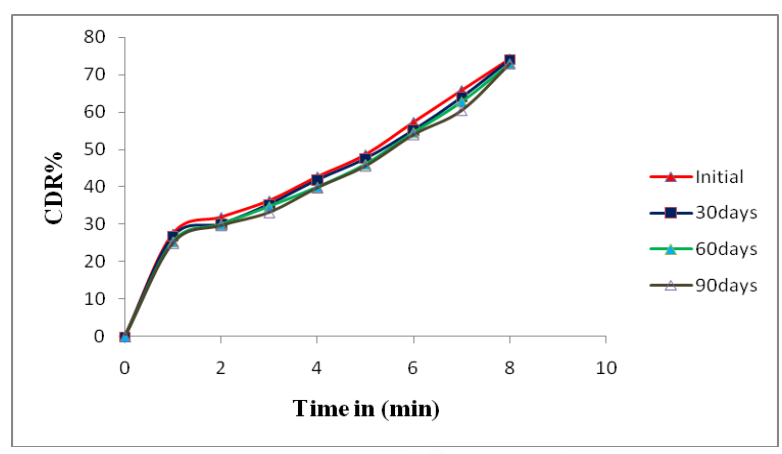

Figure 12. Drug release profile of microsponge gel during stability study

\section{Effect of formulation variables}

\section{Effect of external phase}

The concentration of emulsifier plays a vital role in the preparation of microsponges. The minimum concentration of emulsifier required to formation of uniform and stable microsponges was found to be $0.75 \%$ w/v of external phase. Almost, similar encapsulation efficiency was noticed formulation code F1-F6. When the concentration of emulsifier was decreased from $0.75 \%$ to $0.45 \%$ (F7) production yield, encapsulation efficiency and drug content were increased and the formed microsponges were collapsed after 3 days figure $13 \&$ table 6. Whereas irregular microsponges were formed in the concentration of $0.6 \% \mathrm{w} / \mathrm{v}$ of emulsifier figure $14 \&$ table 6 . When the concentration of emulsifier was increased to $0.9 \%$ and $1 \%$ w/v F9 \& F10 resulted in the more foam formation and it drastically affects production yield, encapsulation efficiency and drug release behavior.

Table 6: Effect of external phase

\begin{tabular}{|c|c|c|c|c|}
\hline Code & $\begin{array}{c}\text { PVA Concentration in } \\
(\mathbf{m g})\end{array}$ & $\begin{array}{c}\text { Production yield } \\
(\boldsymbol{\%}) \pm \text { SD }\end{array}$ & $\begin{array}{c}\text { Encapsulation } \\
\text { efficiency }(\boldsymbol{\%}) \mathbf{\text { SD }}\end{array}$ & \% CDR $\mathbf{\text { SD }}$ \\
\hline F3 & 0.75 & $38.40 \pm 0.39$ & $84.10 \pm 0.03$ & $74.2 \pm 0.46$ \\
\hline F7 & 0.45 & $77.61 \pm 0.02$ & $89.37 \pm 0.21$ & $73.7 \pm 0.29$ \\
\hline F8 & 0.60 & $37.52 \pm 0.11$ & $82.62 \pm 0.01$ & $71.4 \pm 0.23$ \\
\hline F9 & 0.90 & $23.31 \pm 0.17$ & $46.12 \pm 0.02$ & $68.1 \pm 0.27$ \\
\hline F10 & 1.00 & $21.64 \pm 0.15$ & $49.10 \pm 0.01$ & $66.2 \pm 0.32$ \\
\hline
\end{tabular}
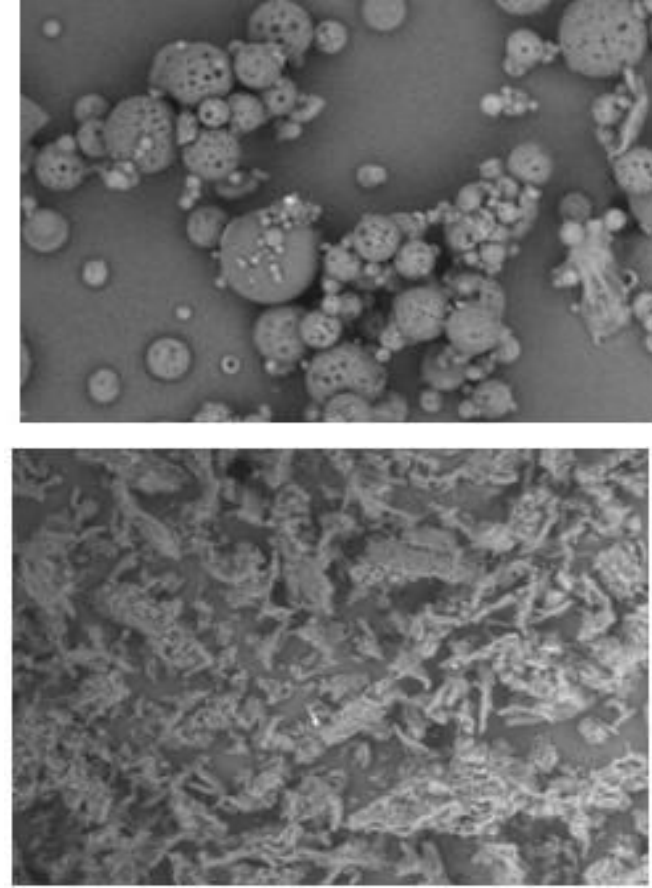

Figure 13: Microsponges at $0.45 \%$ concentration of PVA

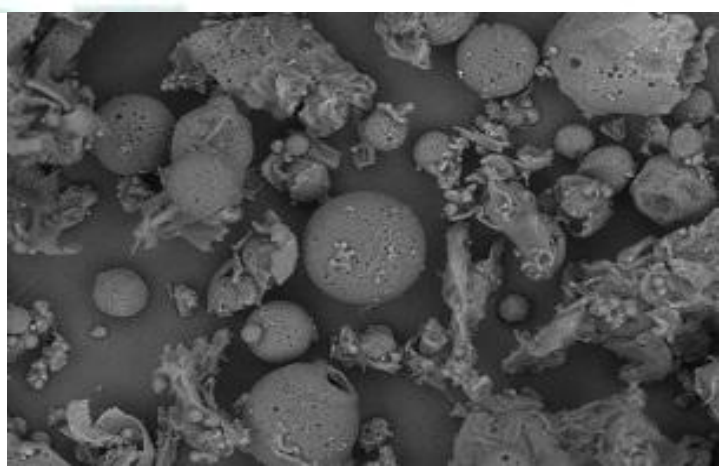

Figure 14: Formation of irregular microsponge using $0.6 \%$ concentration of PVA

\section{Effect of $D / P$ ratio}

Increase in $\mathrm{D} / \mathrm{P}$ ratio has been found to result an increase in production yield; while drug content, encapsulation efficiency and percent drug release were found to be decreased Table 7 . The reason behind that is as $\mathrm{D} / \mathrm{P}$ ratio went on increasing, the polymer amount available for each microsponge to encapsulate the drug was more, thus rising polymer matrix wall thickness which led to an extended diffusion path and ultimately to lesser drug release 
Table 7: Effect of $\mathrm{D} / \mathrm{P}$ ratio

\begin{tabular}{|c|c|c|c|c|c|}
\hline Code & D/P ratio & $\begin{array}{c}\text { Production yield } \\
(\boldsymbol{\%}) \pm \text { SD }\end{array}$ & $\begin{array}{c}\text { Drug } \\
\text { content }(\boldsymbol{\%}) \pm \text { SD }\end{array}$ & $\begin{array}{c}\text { Encapsulation } \\
\text { efficiency }(\boldsymbol{\%}) \pm \text { SD }\end{array}$ & \% CDR \pm SD \\
\hline F1 & $1: 0.5$ & $32.12 \pm 0.21$ & $72.58 \pm 0.01$ & $85.56 \pm 0.01$ & $94.1 \pm 0.01$ \\
\hline F2 & $1: 1$ & $34.60 \pm 0.20$ & $58.02 \pm 0.02$ & $85.12 \pm 0.02$ & $85.1 \pm 0.01$ \\
\hline F3 & $1: 1.5$ & $38.40 \pm 0.39$ & $50.46 \pm 0.01$ & $84.10 \pm 0.03$ & $74.2 \pm 0.02$ \\
\hline F4 & $1: 2$ & $40.00 \pm 0.01$ & $37.23 \pm 0.14$ & $83.42 \pm 0.01$ & $65.1 \pm 0.01$ \\
\hline F5 & $1: 2.5$ & $45.13 \pm 0.04$ & $32.16 \pm 0.02$ & $82.10 \pm 0.03$ & $52.8 \pm 0.03$ \\
\hline F6 & $1: 3$ & $52.24 \pm 0.02$ & $30.16 \pm 0.02$ & $80.10 \pm 0.03$ & $42.7 \pm 0.02$ \\
\hline
\end{tabular}

\section{CONCLUSION}

Microsponge-based novel delivery system has been developed to provide once a day sustained release medication for topical delivery of fluconazole. The method adopted was quasi-emulsion solvent diffusion; found to be simple, reproducible and rapid. Formed microsponges were spherical shape, have high porosity. Different drug-polymer ratio reflected good particle size, drug content and encapsulation efficiency. Microspongebased gel showed viscous and homogenizes preparation and in vitro drug release reflected highest regression value for zero order release model.Microsponge formulated with 1:1.5 drug-polymer ratios were found more efficient to give an extended drug release $74.20 \%$ at the end of $8 \mathrm{~h}$. Gel containing microsponges prepared in this study was found to be promising as new-novel delivery system offering prolonged release of fluconazole in treating fungal infections.

\section{ACKNOWLEDGEMENT}

The authors express a deep sense of gratitude toward RMS Research labs Pvt. Ltd., Hyderabad. India and Yeluri formulations, Hyderabad, India for providing the gift samples of Fluconazole and Ethyl cellulose respectively.

\section{REFERENCES}

1. Vinod LG, Vishal DY Rakesh PD, Prafulla BC, Swapnil DJ 'Effect of Carbopol 934 and 934 on Fluconazole Release from Topical Gel Formulation', C.P.R. 2012; volume 2(2) 487- 493,

2. Helal DA, Dalia Abd El R, Sally A, Abdel H, Mohamed ElNabarawi A, Formulation and evaluation of Fluconazole topical gel International Journal of Pharmacy and Pharmaceutical Sciences volume 4, (Suppl 5), 176-183,

3. Niethard FU, Gold MS, Solomon GS, Liu JM, Unkauf M, Albrecht HH, Elkik F, 2005. Efficacy of topical diclofenac diethylamine gel in osteoarthritis of the knee. The Journal of Rheumatology 32, 2384-2392,

4. Kulkarni RV, Wagh YJ, Setty CM, Sa B, Development and characterization of sodium alginate hydroxypropyl methylcellulose-polyester multilayered hydrogel membranes for drug delivery through skin. Polymer-Plastics Technology and Engineering 2011 volume 50, 490-497,

5. D'souza JI, More HN, Topical anti-inflammatory gels of fluocinolone acetonide entrapped in eudragit based microsponge delivery system Research Journal of Pharmacy and Technology 2008 volume 1, p502-506,
6. Vyas LK, Tapar KK, Laddha BH, Lahoti AO, Nema RK, Formulation and development of anti-blemish preparations using microsponge technology. 2010 Journal of Chemical and Pharmaceutical Research. Volume 2, 562571 ,

7. Vyas SP, Khar RK. Targeted and Controlled Drug Delivery Novel Carrier System, $1^{\text {st }}$ ed. New Delhi CBS Publication; 2002 459-463

8. Won, R. 1987. Method for delivering an active ingredient by controlled time release utilizing a novel delivery vehicle which can be prepared by a process utilizing the active ingredient as a porogen. U.S. Patent 4,690,825

9. Orlu M, Cevher E, Araman A. Design and evaluation of colon specific drug delivery system containing flurbiprofen microsponges. 2006 International Journal of Pharmaceutics Volume 318 103-17,

10. Kilicarslan M, Baykara, T, The effect of the drug/polymer ratio on the properties of verapamil hydrochloride loaded microspheres. 2003 International Journal of Pharmaceutics volume 252, 99-109,

11. Mine O, Erdal, C, Ahmet, A, Design and evaluation of colon specific drug delivery system containing flurbiprofen microsponges 2006. International Journal of Pharmaceutics. Volume 318, 103-117,

12. Formulation and characterization of bupivacaine lipospheres. 2004 Toongsuwan S, Li LC, Erickson BK, Chang HC International Journal of Pharmaceutics Aug 6; 280(1-2):57-65.

13. R. Bhimavarapu, K.P. Chitra, P. Itraconazole loaded microsponges 2011- a novel carrier system International Journal of Pharmaceutical Investigation 1. 67-76

14. Nokhodchi, A., Jelvehgari, M., Reza, S.M., Reza, M.M., 2007. Factors affecting the morphology of benzoyl peroxide microsponges. Micron volume 38, 834-840,

15. Saboji JK, Manvi FV, Gadad AP, Patel BD. Formulation and evaluation of ketocnazole microsponge gel by quasi emulsion solvent diffusion Cell and Tissue Research. 11(1): 2691-6.

16. Bhanu PV, Shanmugam and Lakshmi PK. Development and Optimization of Novel Diclofenac Emulgel for Topical Drug Delivery 2011. International Journal of Comprehensive Pharmacy 9 (10) 1-4.

17. Kumar L and Verma R. In vitro evaluation of topical gel prepared using natural polymer 2010. International Journal of Drug Delivery, 2, 58-63

18. Zaki Rizkalla, C.M., Latif Aziz, R., Soliman, I.I., 2011. Invitro and in vivo evaluation of hydroxyzine hydrochloride microsponges for topical delivery. AAPS Pharmaceutical science and technology. Volume 12, p989-1001.

19. Nirav Patel Niyati Padia Neha Vadgama Mihir Rava Navin Sheth Formulation and evaluation of microsponge gel for topical delivery of fluconazole for fungal therapy Journal of Pharmaceutical Investigation DOI 10.1007/s40005-016-02307

20. Costa P, Lobo JMS. Modeling and comparison of dissolution profiles. 2001 European Journal of Pharmaceutical Sciences. volume 13, 123-133. 